\title{
Systematic Assessment Biases and Effective Property Tax Differentials\#
}

\author{
Sharon Levin*
}

An extensive body of literature has developed on the general theory of property tax incidence. ${ }^{1}$ Nevertheless, many unanswered questions remain. One particular concern is how the assessment process itself contributes to horizontal and vertical inequities and the loss of economic efficiency.

The purpose of this paper is to present some findings on the causes and magnitudes of systematic biases in the assessment of single-family residenas between and within neighborhoods of a multi-jurisdictional assessment district. Previous studies have confined their analyses to a single municipality and assessment district. This paper draws a distinction between intentional and unintentional biases in the process and the resulting horizontal and vertical inequities. Further, the effect of assessment variation on effective property tax differentials is also examined.

\section{ASSESSMENT DISCRIMINATION: AN OVERVIEW}

Systematic biases in the assessment of real property are of interest to students of urban public affairs for several reasons. First, from an economic efficiency standpoint, assessment discrimination may lead to "onerous" tax differentials, that is, rates of taxation which yield no compensating benefits to those compelled to pay them and are in excess of corresponding charges in other localities and/or for other property types. As a result, allocative efficiency may be impaired ${ }^{2}$ as rates of investment in specific property types and/or specific locales are altered.

Two recent studies shed light on this issue. (1) Peterson, et. al. [13], in their study of residential property markets, find substantial variation in the effective property tax rate paid by properties among neighborhoods of the same city due to differential assessment-sales ratios. "A clear pattern emerges in which poor quality housing in blighted neighborhoods, occupied by low-income tenants, pays property taxes at a substantially higher rate than property in other neighborhoods [13, p. 124]." These tax differentials, they conclude, contribute to blight by interfering with the operation of the housing market in such a way that the transfer of properties from poor managers to good managers is hindered, upgrading of existing units is stalled, and run-down strategies are encouraged. (2) In their study of the effect of business taxation on industrial location, Grieson, et. al. [7]

\footnotetext{
*Department of Economics, University of Missouri, St. Louis, Missouri.

\# This research was partially supported by a Summer Research Fellowship from the University of Missouri-St. Louis, and a NSF Science Faculty Professional Development Grant.
} 
find a location elasticity of -.35 for manufacturing activity in New York City with respect to differential local business taxes by property type. They attribute this result to the fact that

manufacturing plants generally partake of little of the economies of agglomeration and scale that nonmanufacturing, office, legal and financial activities obtained in cities, especially one like New York with somewhat unique financial, legal, cultural and communications facilities [7, p. 16].

Second, from a legal perspective, assessment discrimination violates the constitutional and statutory requirements of tax uniformity and equal protection of the law. The basic precepts of equitable taxation, horixontal equity-families in similar circumstances should be taxed equally-and vertical equity-families in different circumstances should be taxed in proportion to their ability-to-pay-may be violated. Previous studies [1, 2, $3,4,5,11,14,17]$, in general, have found that more expensive homes, homes on larger plots, older homes, and homes in neighborhoods with relatively faster increases in price, higher incomes and less non-whites, all tend to be underassessed.

Finally, from a public policy perspective, assessment practices are of interest since it is one of the few areas of local finance seemingly controllable. Several reforms have been suggested and some adopted, but the wheels of reform turn slowly suggesting the need for yet another study of assessment biases and their consequences for equity and economic efficiency.

The empirical analysis proceeds in three parts: (1) an analysis of intraand inter-neighborhood assessment discrimination, (2) an analysis of the types of assessment inequities present, and (3) an analysis of the role that assessment discrimination plays in the formation of effective property tax differentials. A concluding section follows which summarizes the principal findings of this study and their public policy implications.

\section{INTRA- AND INTER-NEIGHBORHOOD ASSESSMENT DISCRIMINATION}

The first step in the analysis is to determine the extent of systematic intra- and inter-neighborhood assessment biases and therefore to determine the degree of pooling (i.e., should data for all neighborhoods be analyzed together?) justifiable in the examination of the nature of the assessment biases. It is well recognized that a large degree of variation exists in the supply and demand for houses across geographic submarkets within an urban area. ${ }^{3}$ The structure of prices and assessed values for houses with particular attributes found in one submarket may be quite different than in another submarket. Previous studies of assessment discrimination have failed to recognize, however, the implications of market segmentation for aggregation bias. If the data are pooled improperly for the estimation of cross-section hedonic price equations, or for that matter, assessed value relationships, then the estimates of assessment inequities will be biased. ${ }^{4}$

Particular care is given toward the definition of neighborhoods in this 
study. Since there exist a large number of governmental units with taxing powers in St. Louis County, Missouri, the study area, it seems logical to identify neighborhoods on the basis of the most important jurisdictions from the standpoint of the supply of and demand for local public goods and services. These are the school district and the municipality. Hence housing units located in the same school district and census place code are grouped together. Neighborhoods, so defined, make more economic sense than the designation of the census tract as the appropriate unit of analysis. The 34 neighborhoods included in this study are listed in Appendix A.

Three possible assessment biases exist: (a) the non-uniform assessment of residential property units with particular characteristics independent of their location, (b) the non-uniform assessment of housing units attributable to their location not their structural characteristics, and (c) the nonuniform assessment of housing units both within (Case a) and between (Case b) neighborhoods.

To test for these effects, the following assessment model is formulated:

$$
\mathrm{A} / \mathrm{P}=\alpha \mathrm{X}_{\mathrm{k}} \beta_{\mathrm{k}} \mathrm{p} \gamma_{\epsilon}
$$

where $\mathrm{A}$ is the assessed value of the house and $\mathrm{P}$ its market value, $\mathrm{X}_{\mathrm{k}}$ is a vector of " $k$ " housing attributes, to be defined below, and $\epsilon$ is a random error term. Taking the natural logarithms of both sides of (1) and rearranging terms results in the following linear relationship:

$$
\begin{gathered}
\ln \mathrm{A}=\alpha^{\prime}+\Sigma_{\mathrm{k}} \beta_{\mathrm{k}} \mathrm{X}_{\mathrm{k}}+(1+\gamma) \ln \mathrm{P}+\epsilon^{\prime} \\
\alpha^{\prime}=\ln \alpha \text { and } \epsilon^{\prime}=\ln \epsilon
\end{gathered}
$$

which can then be estimated for all observations pooled or for observations falling within each neighborhood separately.

This specification is attractive for several reasons. First, its multiplicative nature allows for the impact of each additional structural characteristic on assessed and market value to depend, in a realistic fashion, on the presence of other structural characteristics. Second, the problem of spurious correlation present in estimating equations of the form:

$$
\mathrm{A} / \mathrm{P}=(\mathrm{P}, \mathrm{Z})
$$

where $\mathrm{A}$ and $\mathrm{P}$ are as previously defined, and $\mathrm{Z}$ is a portmanteau variable, need no longer be confronted. The use of such an equation by Black [3] results in a downward bias on the coefficient of $\mathrm{P}$ so that higher priced units will automatically tend to be relatively underassessed, while lower priced units will tend to be overassessed. ${ }^{5}$ Third, the logarithmic transformation reduces the likelihood that heteroscedastic residuals and inefficient parameter estimates, which are often found in cross-section studies, will be present here. ${ }^{6}$. Finally, the transformed coefficients in (2) allow for the straightforward identification of what may be termed intentional and unintentional or latent positive or negative discrimination. Negative coef- 
ficients suggest intentional negative discrimination, assessed valuation moves inversely to the quantity of the housing attribute contained in the housing bundle. Since the coefficients in (2) may be interpreted as elasticities, positive coefficients equal to one indicate assessment uniformity, while positive coefficients greater than or equal to one indicate, respectively, latent discrimination against or latent discrimination in favor of the attribute in question. Thus a test of whether the assessment -sales ratio was not uniform for all housing units, that is, a test for vertical inequity, would be to determine whether $(1+\gamma)$ was significantly different than one.

The basic dataset consists of the sales of more than 25,000 owneroccupied single family homes in St. Louis County, Missouri, during 196572. ${ }^{7}$ Each observation consists of the sales price of the house and its physical description including location. Each observation was then assigned to a school district, census place code, and neighborhood, as discussed previously, and additional neighborhood data recorded. Finally, property tax rates and assessed values were determined for those units sold during 1970. The resulting sample contains approximately 1400 house sales. The variables used in the analysis and their sources are described in Table 1.

Analysis of variance is used to test for the estent of systematic intra-and inter-neighborhood assessment discrimination. Housing attributes included in the actual estimation of (2) are LOTSIZE, LIVAREA, and YRBUILT. ${ }^{8}$ The appropriate F-test ${ }^{9}$ indicates that the null hypothesis of intra- and inter-neighborhood assessment homogeneity (Case c, above) must be rejected at a level of significance exceeding $.01 ; \mathrm{F}$-test $=3.298$. But when the intercept of the log-linear relationship (2) is allowed to vary by neighborhood (by the inclusion of $\mathrm{N}-1$ dummy variables, where $\mathrm{N}=$ the number of neighborhoods), then the null hypothesis of homogeneity in the slope coefficient for each attribute (Case a, above) cannot be rejected; F-test $=.025$. Correspondingly, the null hypothesis of homogeneity of the intercepts between neighborhoods, once slope coefficients are assumed to be equal, must also be rejected; F-test $=18.110$. Thus it is feasible to pool the observations and discuss assessment biases for different housing attributes only if the differences between neighborhood 'characteristics are controlled for.

\section{THE NATURE OF ASSESSMENT DISCRIMINATION}

Equation (4) shows the results of estimating equation (2) with dummy variables controlling for neighborhood differences.

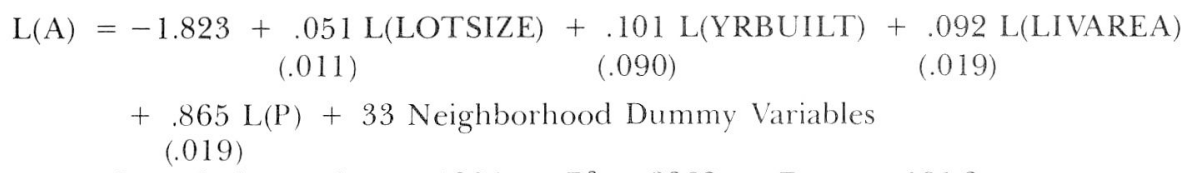


TABLE 1

DESCRIPTION OF VARIABLES

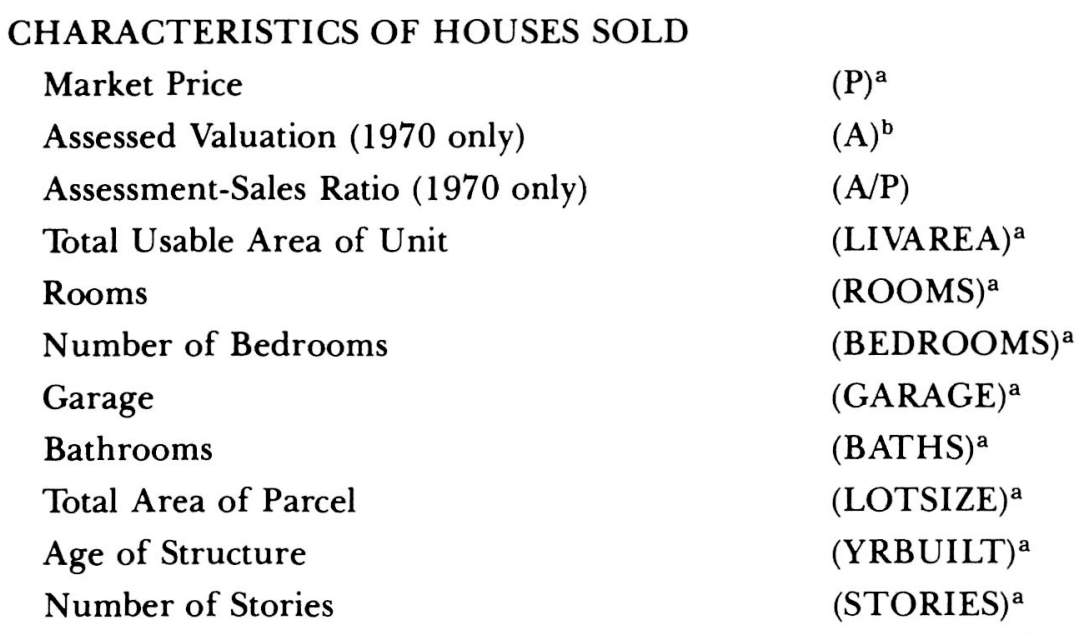

CHARACTERISTICS OF NEIGHBORHOODS (1970)

Percentage of Year-Round Housing Units Vacant

$(\mathrm{VAC})^{\mathrm{c}}$

Percentage of Occupied Units Renter-Occupied

$(\text { RENT) })^{\mathrm{c}}$

Percentage of Year-Round

Housing Units in Single Unit

Structures

$(\text { ONEFAM })^{\mathrm{c}}$

Population Density -

hundreds per sq. mile

$(\mathrm{DEN})^{\mathrm{c}}$

Percentage of Population

Non-white

$(\mathrm{NWP})^{\mathrm{c}}$

Percentage Change in

Neighborhood Sales Prices

1965-1969

$(\text { PTREND })^{\mathrm{a}}$

Nominal Property Tax Rate per $\$ 100$

of Assessed Valuation

$(\text { TAXRATE })^{\mathrm{b}}$

Effective Property Tax Rate -

(TAXRATE X A)/P as \%

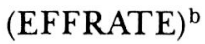

Index of Municipal Park Services

$(\text { PARK })^{d}$

\footnotetext{
Sources: (a) Real Estate File of the St. Louis Office Federal Housing Administration

(b) Assessor's Office, St. Louis County Department of Planning

(c) Census of Population (1970) and Census of Housing (1970)

(d) St. Louis County Department of Parks and Recreation
} 
All of the coefficients, with the exception of L(YRBUILT), are significantly different than zero (one in the case of $L(P)$ ) at a level of confidence exceeding .99. The results suggest latent discrimination in favor of homes on larger parcels, and larger and newer homes. The coefficient of $\mathrm{L}(\mathrm{P})$, .865 , is significantly different than one; hence assessed values do not rise as fast as market values. Thus, the assessment-sales ratio falls as the value of the home rises and people who consume more housing services per housing unit, those presumably with higher incomes, will experience lower effective tax rates, ceteris paribus, than those who consume relatively less housing services per unit, those presumably with lower incomes.

It is also instructive to determine the neighborhood factors associated with the differential intercepts in equation (4). Previous studies suggest that the following factors, other things being equal, ought to be related to assessment differences by neighborhood: (1) past neighborhood price trends (PTREND) - the laxity in assessment administration suggests that neighborhoods in which prices rise faster than average should find themselves with relatively lower assessed values, (2) the percentage of non-white residents in a neighborhood (NWP)-racial discrimination, and (3) the presence of amenities such as parks (PARK) and conforming house-types (ONEFAM) and disamenties such as vacant housing units (VACANT) and rental housing units (RENT) - the benefit principle of public finance suggests that amenities should be directly related to assessed and market values while disamenities should be inversely related to these values, but the assessor may evaluate these factors differently than the market.

Equation (5) shows the results of substituting these neighborhood parameters for the dummy variables included in equation (4).

$$
\begin{aligned}
& \mathrm{L}(\mathrm{A})=-.441+\underset{(.011)}{.043 \mathrm{~L}(\mathrm{LOTSIZE})+\underset{(.093)}{.130 \mathrm{~L}(\text { YRBUILT })+}+.079 \mathrm{~L}(\text { LIVAREA })} \\
& +.892 \mathrm{~L}(\mathrm{P})+.028 \mathrm{~L}(\mathrm{PTREND})+.002(\mathrm{PARK})-.366 \mathrm{~L}(\mathrm{ONEFAM}) \\
& \begin{array}{llll}
(.019) \quad(.009) & (.000)
\end{array} \\
& +.027 \mathrm{~L}(\mathrm{NWP})-.046 \mathrm{~L}(\mathrm{RENT})-.062 \mathrm{~L}(\mathrm{VAC}) \\
& \begin{array}{lll}
(.003) \quad(.015) \quad(.015)
\end{array}
\end{aligned}
$$

Number of Observations $=1394 \quad \mathrm{R}^{2}=.8250 \quad$ F-test $=652.1$

The coefficients of the housing attributes previously included in equation (4), LOTSIZE, YRBUILT, LIVAREA and P, are not changed markedly by this procedure indicating that the neighborhood factors specified do make important additional contributions to the explanation of the variation in assessed values. All the coefficients of the neighborhood factors are significantly different than zero at confidence levels exceeding .99. The laxity in administration is again seen to be a significant determinant of assessment bias; the coefficient of L(PTREND) suggests that differences of 10 percent in neighborhood rates of price changes results in assessed values differing by only .3 percent. In addition, the assessment procedure, in general, 
favors neighborhoods with larger percentages of their housing stock in one-family structures and neighborhoods with fewer non-white residents, fewer housing units which are renter-occupied, and fewer housing units which are vacant.

\section{ASSESSMENT DISCRIMINATION AND EFFECTIVE TAX RATES}

Assessments are related to effective property tax rates in the following manner:

\section{$\mathrm{A} / \mathrm{P} \times \mathrm{TAXRATE} \equiv \mathrm{EFFRATE}$}

where the terms are as defined in Table 1. Thus part of the variation in effective property tax rates can be attributed to the variation in assessment-sales ratios caused by assessment inequities. Of course, to the extent that nominal tax rates and assessment-sales ratios are colinear, it will be difficult to measure the separate contribution that each makes in determining the variation in effective tax rates. Since the simple correlation coefficient between $\mathrm{A} / \mathrm{P}$ and TAXRATE is just .028, in this study, which is not significantly different from zero, a farily good estimate of the contribution each makes in explaining the variation in effective tax rates is obtained just from their simple coefficients of determination with respect to EFFRATE. These are, respectively, for A/P and TAXRATE, 734 and .286, hence; the variation in assessment-sales ratios accounts for 73.4 percent while the variation in nominal tax rates accounts for 28.6 percent of the variation in effective tax rates. The total amount of variation in effective tax rates explained by this procedure exceeds 100 percent because TAXRATE and A/P are correlated. If the covariation between TAXRATE and A/P is entirely attributed to the variation in nominal rates, then a lower bound for the estimate of the contribution that assessment biases make in determining the variation in effective tax rates is 70.9 percent. If, on the other hand, the covariance between A/P and TAXRATE is entirely attributed to the variation in $\mathrm{A} / \mathrm{P}$, then the maximum contribution that the variation in $\mathrm{A} / \mathrm{P}$ makes in explaining the variation in effective tax rates is still 73.4 percent. Thus assessment inequities account for between 70.9 and 73.4 percent of the variation in effective tax rates in the sample studied.

\section{SUMMARY AND CONCLUSIONS}

This study finds evidence of both intra- and inter-neighborhood assessment biases. More expensive homes, larger and newer homes, as well as homes on larger land parcels, all tend to be relatively underassessed. Furthermore, the assessment process appears to favor homes in neighborhoods which have experienced faster increases in prices, neighborhoods which have larger percentages of their stock in single-family structures, and neighborhoods which have fewer non-white residents, fewer renteroccupied units, and fewer vacancies. As a result, this study finds that approximately 70 percent of the variation in effective property tax rates across the 34 neighborhoods examined can be attributed to the variation in 
assessment-sales ratios. Thus the potential impact of assessment reform is large.

Of course, to the extent that differences in effective property tax rates are likely to be fully capitalized-the evidence to date is still inconclusivethen horizontal inequity would no longer be an issue. That is, a home bearing a lower tax burden than a similar home, other things being equal, would find that its sales value rises until its tax advantage is just offset by its higher value. But there is no guarantee, however, that the market works in such a way that ensures vertical equity. It may well be that capitalization accentuates regressivity as owners of favorably treated properties realize capital gains while those discriminated against suffer relative losses. In conclusion, there is a great need for assessment reform and perhaps then much of the criticism of the property tax would subside.

\section{FOOTNOTES}

${ }^{1}$ See, for instance, Jens Peter Jensen, Property Taxation in the United States (Chicago: University of Chicago Press, 1931); Peter Mieszkowski, "The Property Tax: An Excise Tax or a Profits Tax," Journal of Public Economics 1 (April 1972): 73-96; Dick Netzer, Economics of the Property Tax (Washington, D,C,: The Brookings Institution, 1966); and Dick Netzer, "The Incidence of the Property Tax Revisited," National Tax Journal 26 (December 1973): 515-35.

${ }^{2}$ Allocative efficiency will in general impaired unless the cnercus local tax internalizes the spillover costs of pollution or other diseconomics created by firms, or offsets other local discriminatory charges.

${ }^{3}$ See, for instance the studies by Schnare and Struyk [16] and Straszheim [18]

${ }^{4}$ The study -by Berry and Bednarz [1], is, for example, subject to this criticism. Little's work [10] as well as Edelstein's [4] have also ignored the biases resulting from market segmentation and improper pooling. In fact, if pooling can not be justified, then the twostage least-squares estimating procedure employed by Edelstein is invalid.

${ }^{5} \mathrm{As}$ a result, his estimate of racial discrimination in the assessment process, which is indicated by the coefficient on $N$ (non-white population density) will be biased upward.

${ }^{6}$ Standard empirical tests for heteroscedasticity proved inconclusive. If heteroscedasticity was present, the validity of the F-tests for pooling may be invalid, since the maintained hypothesis of these tests is that the error variances be the same for the unrestricted and restricted regressions (see note 9 ).

${ }^{7}$ The basic dataset was kindly made available to me by James Little, Washington University, St. Louis.

${ }^{8}$ To economize, only the most consistent and important determinants of house value as empirically determined, were included in these regressions. Other characteristics considered are listed in Table 1.

${ }^{9}$ To summarize the practical procedures, all covariance tests are based on comparisons between pairs of three basic regressions:

(1) $\mathrm{Y}$ on $\mathrm{X}$, restricted so that slopes and intercepts are equal between all neighborhoods (subgroups),

(2) $\mathrm{Y}$ on $[\mathrm{D} \mathrm{X}]$, where the intercepts are allowed to differ by neighborhood but restricted so that the slopes are equal, and
(3) Y on $\mathrm{X}$ separately for each neighborhood, unrestricted regression.

All F-tests are tests of the reduction in unexplained variance (RSS) going from a restricted regression (1 or 2 ) to an unrestricted regression. The basic F-test is then:

(Restricted RSS - Unrestricted RSS)/degrees of freedom Unrestricted RSS/degrees of freedom

For further discussion, see Johnston [9, p. 194].

${ }^{10}$ Two of these variables require further discussion. PARK is a Schmandt-Stephens [15] index of municipal output. Specifically, each municipality was assigned the value of one for each major ( $\geqslant 30$ acres) municipal park it had and one additional point for each different activity provided by the park(s). Higher index values imply greater output. PTREND is estimated independently for each neighborhood to avoid aggregation bias with an hedonic price equation of the form:

$$
1_{n} P_{i t}=a_{o}+a_{1} X_{1}+a_{2} X_{2}+\ldots a_{t} D_{U} M_{t}+U_{i t} .
$$

The $\mathrm{X}$ vector $\left(\mathrm{X}_{1}, \mathrm{X}_{2}, \ldots \mathrm{X}_{n}\right)$ identifies attributes of house $\mathrm{i}$ at time $\mathrm{t}, \mathrm{P}_{\mathrm{it}}$ is the sales price of house $\mathrm{i}$ at time $\mathrm{t}$, and $\mathrm{DUM}_{\mathrm{t}}$ is a dummy variable equal to one in year $\mathrm{t}$, or zero otherwise, which serves to shift the intercept in year $t$ The years 1965-69 are included in the analysis of neigh borhood house trends; thus there are four dummy variables, one for each of the years 1966-69, in each equation-1965 is the base year. The coefficient for each dummy variable can be interpreted as the average percentage change in neighborhood prices since 1965 , holding housing quality constant. This method, in effect, uses average weights to correct for quality change and the average weights are simply the coefficients of the $\mathrm{X}$ vector obtained from the regression that provides the best fit to the data throughout the period studied. For a complete discussion of this techniques, see Griliches [8]. The "best fit" is determined by a stepwise regression procedure known as Max $\mathrm{R}^{2}$ improvement, in which the dummy variables are always forced in. A discussion of this technique is found in Jolayne Service, SAS, A User's Guide to the Statistical Analysis System (Raleigh, N.C., North Carolina State Univ., August 1972), page 128.

${ }^{11}$ For a discussion of this procedure, and the properties of orthogonal regressors, see Goldberger $[6$, $192-201]$ 
APPENDIX A

NEIGHBORHOODS IN THE STUDY

CENSUS PLACE

Affton (U)

Ballwin

Bellefontaine Neighbors

Bel-Ridge

Berkeley

Breckenridge Hills

Brentwood

Bridgeton

Crestwood

Ferguson

Florissant

Florissant

Glendale

Hazelwood

Jennings

Kirkwood

Lemay (U)

Lemay (U)

Maplewood

Maryland Heights (U)

Northwoods

Overland

Pinelawn

Richmond Heights

Rock Hill

Saint Ann

Saint Ann

Saint John

Sappington

Spanish Lake (U)

Sunset Hills

University City

Webster Groves

Woodson Terrace
SCHOOL DISTRICT

Affton

Rockwood R-6

Riverview Gardens

Normandy

Berkeley

Ritenour

Brentwood

Pattonville

Lindbergh

Ferguson R-2

Ferguson R-2

Hazelwood

Kirkwood R-7

Hazelwood

Jennings

Kirkwood R-7

Hancock Place

Mehlville R-9

Maplewood-Richmond Heights

Pattonville

Normandy

Ritenour

Normandy

Maplewood-Richmond Heights

Webster Groves

Pattonville

Ritenour

Ritenour

Lindbergh

Hazelwood

Lindbergh

University City

Webster Groves

Ritenour

$\mathrm{U}=$ Unincorporated Area, 1970 


\section{REFERENCES}

1. Berry, B. and Bednarz, R. "A Hedonic Model of Prices and Assessments for Single-Family Homes: Does the Assessor Follow the Market or the Market Follow the Assessor?" Land Economics 51 (February 1975): $21-40$.

2. Black, David E. "The Nature and Extent of Effective Property Tax Rate Variation Within the City of Boston." National Tax Journal 25 (June 1972): 203-10.

3. . "Causes of Local Property Tax Discrimination." Southern Economic Journal 44 (January 1977): 1313-20.

4. Edelstein, Robert. "The Determinants of Value in the Philadelphia Housing Market: A Case Study of the Main Line 1967-69. "Review of Economics and Statistics" 56 (August 1974): 319-28.

5. Engle, Robert F. "DeFacto Discrimination in Residential Assessments: Boston." National Tax Journal 28 (December 1975): 445-51.

6. Goldberger, Arnold S. Econometric Theory. New York: John Wiley and Sons, 1964

7. Grieson, Ronald E., Hamovitch, William; Levinson Albert M., and Morgenstern, Richard D. "The Effect of Business Taxation on the Location of Industry: An Econometric and Theoretical Investigation." Joumal of Urban Economics 3 (July 1977) 272-91.

8. Griliches, Zvi. "Hedonic Price Indexes for Automobiles: An Econometric Analysis of Quality Change." In The Price Statistics of the Federal Government, Pp. 173-96. New York: National Bureau of Economic Research, 1962

9. Johnston, J. Econometric Methods. 2nd ed. New York: McGraw-Hill Book Company, 1972.

10. Little, James T.; Nourse, Hugh O., and Phares, Donald. The Neighborhood Succession Process. St. Louis, Missouri: Institute for Urban and Regional
Studies of Washington University for the Department of Housing and Urban Development, 1974.

11. Oldman, Oliver, and Aaron, Henry. "AssessmentSales Ratios under the Boston Property Tax." National Tax Journal 18 (March 1978): 36-49.

12. Peterson, George E. "The Property Tax and LowIncome Housing Markets." In Property Tax Reform, pp. 110-24. Edited by George E. Peterson. Washington, D.C.: The John C. Lincoln Institute and The Urban Institute, 1973

13. Peterson, George E.; Solomon, A.P.; Madjid, H., and Apgar, W. C. Property Taxes, Housing and the Cities. Lexington, Mass.: D. C. Heath-Lexington Books, 1974.

14. Pollakowski, Henry O. "Sources of Systematic Error in the Assessment of Urban Residential Property." In Proceedings of the Sixty-Ninth Aninual Conference on Taxation, pp. 89-96. Columbus, Ohio: National Tax Association-Tax Institute of America, 1977.

15. Schmandt, Henry, and Stephens, G. R., "Measuring Municipal Output." National Tax Journal 13 (December 1960): $369-75$

16. Schnare, A. B. and Struyk, R., "Segmentation in Urban Housing Markets." Journal of Urban Economics 2 (April 1976): 146-66.

17. Schroeder, Larry D. and Sjouquist, David L. “An Investigation of the Causes of Property Tax Assessment Ratio Variation in the City of Atlanta." (Mimeo)

18. Straszheim, Marion. "Hedonic Estimation of Housing Market Prices: A Futher Comment." Review of Economics and Statistics 56 (August 1974): 319-28.

19. Wales, T. J. and Wiens, E. G., "Capitalization of Residential Property Taxes: An Empirical Study." Review of Economics and Statistics 56 (August 1974): 329-33. 